\title{
AS EMPRESAS SÃO GRANDES COLEÇÕES DE PROCESSOS
}

José Ernesto Lima Gonçalves

Professor do Departamento de Administração Geral e Recursos Humanos da EAESP/FGV e Consultor.

E-mail: jernesto@fgvsp.br

\section{RESUMO}

A idéia de processo tem estado presente nos textos e nas discussões sobre Administração de Empresas nos últimos anos. É praticamente impossível evitar temas como redesenho de processos, organização por processos e gestão por processos. Essa idéia, no entanto, não é nova e tem raízes na tradição da engenharia industrial e no estudo dos sistemas sociotécnicos. Embora muito presente, o conceito de processo não tem uma interpretação única, e a variedade de significados encontrados tem gerado inúmeros mal-entendidos. Este artigo propõe-se a facilitar a compreensão do assunto, oferecendo um quadro organizado de definições e aplicações para o conceito de processo empresarial.

\section{ABSTRACT}

The idea of process has been present in most texts and discussions on business and management in the last years. It is almost impossible to avoid subjects like process re-design, process-centered organizations and process management. This idea, however, is not new and has its origins in the industrial engineering tradition and in the studies on sociotechnical systems. Although very common, the concept of process has not a unique interpretation, and the variety of meanings that can be found has generated many misunderstandings. This article intends to facilitate the comprehension of the subject, offering an organized framework of definitions and applications for the concept of business process.

PALAVRAS-CHAVE

Processo, redesenho de processos, organização por processos, gestão por processos, geração de valor.

\section{KEY WORDS}

Process, process re-design, process organization, process management, value generation. 


\section{O QUE SÃO OS PROCESSOS NAS EMPRESAS}

Todo trabalho importante realizado nas empresas faz parte de algum processo (Graham e LeBaron, 1994). Não existe um produto ou um serviço oferecido por uma empresa sem um processo empresarial. Da mesma forma, não faz sentido existir um processo empresarial que não ofereça um produto ou um serviço.

Na concepção mais freqüente, processo é qualquer atividade ou conjunto de atividades que toma um input, adiciona valor a ele e fornece um output a um cliente específico. Os processos utilizam os recursos da organização para oferecer resultados objetivos aos seus clientes (Harrington, 1991). Mais formalmente, um processo é um grupo de atividades realizadas numa seqüência lógica com o objetivo de produzir um bem ou um serviço que tem valor para um grupo específico de clientes (Hammer e Champy, 1994).

Essa idéia de processo como um fluxo de trabalho - com inputs e outputs claramente definidos e tarefas discretas que seguem uma sequiência e que dependem umas das outras numa sucessão clara - vem da tradição da engenharia (que também deu origem à idéia de reengenharia). Os inputs podem ser materiais - equipamentos e outros bens tangíveis -, mas também podem ser informações e conhecimento. Nessa visão, os processos também têm início e final bem determinados. Essa abordagem, característica dos adeptos do aperfeiçoamento de processos (Harrington, 1991), acompanhou o raciocínio da engenharia industrial.

No entanto, o fluxo de trabalho é apenas um dos tipos de processo empresarial, talvez aquele em que as atividades são mais interdependentes e realizadas numa seqüência específica. Essa definição estrita deixa de fora processos que não têm início e fim claros ou cujo fluxo não é bem definido. Às vezes, alguns desses processos têm impacto maior que os demais na própria viabilidade da empresa, como aqueles ligados à sucessão na empresa, ao desenvolvimento dos gerentes e à avaliação do desempenho do pessoal.

Os cinco modelos básicos de processos empresariais formam um espectro que abrange desde o mais concreto e objetivo modelo, baseado no fluxo de materiais, até o modelo mais abstrato, que se fundamenta na mudança de estados de um sistema. O Quadro 1 resume as principais características desses modelos e oferece exemplos.

Assim, nem sempre os processos empresariais são formados de atividades claramente delineadas em termos de conteúdo, duração e consumo de recursos defi-

Quadro 1 - Espectro dos principais modelos de processos

\begin{tabular}{|c|c|c|}
\hline Processo como & Exemplo & Características \\
\hline Fluxo de material & $\begin{array}{l}\text { Processos de fabricação } \\
\text { industrial }\end{array}$ & $\begin{array}{l}\text { - inputs e outputs claros } \\
\text { - atividades discretas } \\
\text { - fluxo observável } \\
\text { - desenvolvimento linear } \\
\text { - seqüência de atividades }\end{array}$ \\
\hline Fluxo de trabalho & $\begin{array}{l}\text { Desenvolvimento de produto } \\
\text { Recrutamento e contratação de } \\
\text { pessoal }\end{array}$ & $\begin{array}{l}\text { - início e final claros } \\
\text { - atividades discretas } \\
\text { - seqüência de atividades }\end{array}$ \\
\hline Série de etapas & $\begin{array}{l}\text { Modernização do parque } \\
\text { industrial da empresa } \\
\text { Redesenho de um processo } \\
\text { Aquisição de outra empresa }\end{array}$ & $\begin{array}{l}\text { - caminhos alternativos para o resultado } \\
\text { - nenhum fluxo perceptível } \\
\text { - conexão entre atividades }\end{array}$ \\
\hline $\begin{array}{l}\text { Atividades } \\
\text { coordenadas }\end{array}$ & $\begin{array}{l}\text { Desenvolvimento gerencial } \\
\text { Negociação salarial }\end{array}$ & $\begin{array}{l}\text { - sem seqüência obrigatória } \\
\text { - nenhum fluxo perceptível }\end{array}$ \\
\hline Mudança de estados & $\begin{array}{l}\text { Diversificação de negócios } \\
\text { Mudança cultural da empresa }\end{array}$ & $\begin{array}{l}\text { - evolução perceptível por meio de indícios } \\
\text { - fraca conexão entre atividades } \\
\text { - durações apenas previstas } \\
\text { - baixo nível de controle possível }\end{array}$ \\
\hline
\end{tabular}


nidos, nem precisam ser consistentes ou realizados numa seqüência particular (Morris e Brandon, 1994). Muitas vezes e por diversos motivos, é mais interessante organizar os processos por etapas. É o caso, por exemplo, dos processos de modernização empresarial ou de diversificação de negócios e de projetos de consultoria empresarial. Muitos autores, na verdade, entendem que as atividades de diversos processos empresariais são apenas inter-relacionadas e que a essência dos processos é a coordenação das atividades (Graham e LeBaron, 1994). É o caso de processos de sucessão empresarial, desenvolvimento de tecnologia e negociação salarial.

\section{OS PROCESSOS NÃO FABRIS NAS EMPRESAS}

A intensa utilização do conceito de processo na modernização das empresas provavelmente tem origem na tentativa de aplicação no ambiente de escritório das técnicas de aperfeiçoamento do trabalho que foram desenvolvidas para o ambiente industrial (Gonçalves, 1990).

Os processos na área fabril são fáceis de se observar, tanto nos períodos de bom funcionamento como na ocorrência de problemas. O desperdício e o retrabalho são claramente identificáveis, e o fluxo do material é tão importante que os equipamentos e equipes de trabalho são dispostos ao longo dele. Toda uma ciência de aperfeiçoamento dos processos industriais foi desenvolvida ao longo de décadas, chegando, inclusive, a ser aplicada a situações de trabalho nos escritórios.

Atualmente, no entanto, o trabalho nos escritórios segue um fluxo conduzido pelos cabos da rede informatizada, e o deslocamento do trabalho não é tão facilmente observável.

Muitas vezes, o funcionamento das empresas exige a organização de processos provisórios, de duração limitada. Geralmente, es-

Observamos, também, que os passos de certos processos organizacionais não precisam ser cuidadosamente definidos nem consistentes ou realizados numa seqüência particular (Morris e Brandon, 1994).

Outros processos organizacionais correspondem a um grupo de atividades que ocorrem ao longo do tempo, como, por exemplo, o processo de amadurecimento de uma pessoa, o processo de modernização da indústria bancária ou o processo de estruturação de uma rede de lojas ao longo de 25 anos.

Processo empresarial também pode ser definido como qualquer trabalho que seja recorrente, afete algum aspecto da capacitação da empresa (organizational capability), possa ser realizado de várias maneiras distintas com resultados diferentes em termos da contribuição que pode gerar com relação a custo, valor, serviço ou qualidade e envolva a coordenação de esforços para a sua realização (Keen, 1997).

Em função da interdisciplinaridade característica da Administração de Empresas, é importante reconhecer o emprego da palavra "processo" em outras áreas do conhecimento. Encontramos a palavra sendo empregada na Sociologia, na Psicologia, na Biologia, na Arquitetura, na Engenharia e na Política, sempre com acepções semelhantes, embora tratando de assuntos muito diferentes. ses processos provisórios são horizontais, embora alguns times horizontais sejam bastante duradouros, especialmente aqueles ligados a atendimento de pedidos, treinamento de pessoal-chave, geração de novos negócios e inovação (Lipnack e Stamps, 1997).

Olhando de outra maneira, os processos empresariais são atividades coordenadas que envolvem pessoas, procedimentos e tecnologia. Na verdade, os processos em geral, e em particular, de negócio representam uma nova abordagem à coordenação de atividades ao longo da empresa (Malhorta, 1998). Pensar nos processos em termos de coordenação em vez de fluxos de trabalho ou fluxos físicos de materiais ou produtos, como tem sido a abordagem predominante na reengenharia e no TQM (Total Quality Management) (Keen, 1997), é importante para poder identificar e tratar processos não industriais como importantes ativos de negócio e para poder analisar qualquer tipo de processo.

Num sentido mais amplo, chamamos de processo de trabalho a maneira particular de realizar um determinado conjunto de tarefas, sob o ponto de vista dos especialistas em análise do trabalho humano (Cameron et al., 1995). Dessa forma, a definição inclui não apenas as tarefas a serem executadas mas também o número de operadores, a distribuição do trabalho entre 
eles, a tecnologia empregada, os indicadores de eficiência e os resultados esperados. Liga-se também à noção de método de trabalho (Lowenthal, 1994). Os processos podem ser entendidos popularmente como "a forma pela qual as coisas são feitas na empresa" (Lipnack e Stamps, 1997), e a maneira mais abrangente de definir processo empresarial é "como produzir alguma coisa" (Malone et al., 1997).
Por outro lado, algumas vezes, as atividades essenciais (aquelas atividades que são críticas para que sejam atingidos os objetivos da empresa) podem ser chamadas de processos. Elas envolvem um conjunto de atividades operacionais, diversos níveis organizacionais e práticas gerenciais. Assim, elas são os processos que precisam ser executados para que a empresa exista (Bennis e Mische, 1995). O Quadro 2 mostra

Quadro 2 - Exemplos de processos empresariais selecionados

\begin{tabular}{|c|c|c|}
\hline Família de processos & \multicolumn{2}{|c|}{ Processos selecionados } \\
\hline Administração geral & $\begin{array}{l}\text { - Definição de visão } \\
\text { - Desenvolvimento de lideranças } \\
\text { - Gerência de contas }\end{array}$ & $\begin{array}{l}\text { - Comunicações internas } \\
\text { - Projeções econômicas e setoriais }\end{array}$ \\
\hline Manufatura & $\begin{array}{l}\text { - Gestão da qualidade } \\
\text { - Planejamento da capacidade } \\
\text { - Planejamento da produção }\end{array}$ & $\begin{array}{l}\text { - Controle de estoques } \\
\text { - Suprimentos } \\
\text { - Distribuição }\end{array}$ \\
\hline Marketing & $\begin{array}{l}\text { - Definição de preços } \\
\text { - Gestão de canal } \\
\text { - Introdução de produtos }\end{array}$ & $\begin{array}{l}\text { - Pesquisa de marketing } \\
\text { - Planejamento de propaganda }\end{array}$ \\
\hline Educacionais & $\begin{array}{l}\text { - Desenvolvimento de habilidades } \\
\text { - Educação do consumidor }\end{array}$ & - Desenvolvimento gerencial \\
\hline $\begin{array}{l}\text { Desenvolvimento de } \\
\text { tecnologia }\end{array}$ & $\begin{array}{l}\text { - Pesquisa e desenho } \\
\text { - Avaliação de tecnologia } \\
\text { - Seleção de novos produtos }\end{array}$ & $\begin{array}{l}\text { - Definição de padrões } \\
\text { - Gestão de projetos } \\
\text { - Teste de protótipos }\end{array}$ \\
\hline Financeiros & $\begin{array}{l}\text { - Gestão de orçamento empresarial } \\
\text { - Planejamento de investimentos } \\
\text { - Acompanhamento do desempenho }\end{array}$ & $\begin{array}{l}\text { - Gestão de crédito de clientes } \\
\text { - Gestão de caixa } \\
\text { - Desmobilização de ativos }\end{array}$ \\
\hline Organizacionais & $\begin{array}{l}\text { - Planejamento de recursos humanos } \\
\text { - Programa de demissão voluntária } \\
\text { - Recrutamento e seleção }\end{array}$ & $\begin{array}{l}\text { - Avaliação de desempenho } \\
\text { - Promoção }\end{array}$ \\
\hline Legais & - Regulamentação & - Registro e controle de patentes \\
\hline De aliança & - Gestão de parcerias & - Joint ventures \\
\hline Comerciais & $\begin{array}{l}\text { - Incentivos e recompensas para força } \\
\text { de vendas }\end{array}$ & $\begin{array}{l}\text { - Marketing direto } \\
\text { - Gestão de filiais }\end{array}$ \\
\hline $\begin{array}{l}\text { Gerenciamento de } \\
\text { linha de produto }\end{array}$ & $\begin{array}{l}\text { - Gestão de produto específico } \\
\text { - Consultoria }\end{array}$ & - Outsourcing \\
\hline De suporte ao cliente & $\begin{array}{l}\text { - Suporte técnico } \\
\text { - Gestão de instalações }\end{array}$ & $\begin{array}{l}\text { - Garantia } \\
\text { - Reparo }\end{array}$ \\
\hline
\end{tabular}

Fonte: Adaptado de Peter Keen (1997). 
uma coleção abrangente de sistemas empresariais selecionados. É notável a variedade de processos que podemos encontrar nas empresas.

A definição de processo pela descrição da transformação de inputs em outputs de valor não é suficiente para especificar o assunto que interessa. Um processo típico também envolve endpoints, transformações, feedback e repetibilidade. As transformações ocorridas num processo podem ser físicas, de localização e transacionais (transformação de itens não tangíveis).

namento de determinados indivíduos e grupos nas organizações. ${ }^{1} \mathrm{O}$ pessoal de Organização chama esses padrões de interação de processos organizacionais.

\section{TIPOS DE PROCESSOS}

Às vezes, é interessante separar os processos de produção dos bens e serviços oferecidos dos demais processos que ocorrem na empresa: os processos relacionados com a gestão da empresa e os de apoio aos processos produtivos (Harrington, 1991).

Existem três categorias básicas de processos empresariais: ${ }^{2}$ os processos de negócio (ou de cliente) são aqueles que caracterizam a atuação da empresa e que são suportados por outros processos internos, resultando no produto ou serviço que é recebido por um cliente externo; os processos organizacionais ou de integração organizacional são centralizados na organização e viabilizam o funcionamento coordenado dos vários subsistemas da organi-

O emprego de todos esses atributos na definição do processo permite garantir condições mais adequadas para a sua análise e gestão.

As características básicas dos processos ajudam a ilustrar as diferenças entre os processos de manufatura e os de serviços, conforme pode ser observado no Quadro 3.

A regularidade do padrão de interação entre os indivíduos da organização leva ao surgimento de um modelo razoavelmente definido de regras e comportamentos, que é essencial para a estabilização do funcio- zação em busca de seu desempenho geral, garantindo o suporte adequado aos processos de negócio; e os processos gerenciais são focalizados nos gerentes e nas suas relações (Garvin, 1998) e incluem as ações de medição e ajuste do desempenho da organização.

A classificação geral dos processos empresariais, juntamente com suas principais características e exemplos, é apresentada no Quadro 4. Cada categoria se subdivide em tipos de processos, que se distinguem uns dos outros em função da sua capacidade de gerar valor, do fluxo básico, da atuação e da orientação bá-

Quadro 3 - Características distintas dos processos de serviços e de manufatura

\begin{tabular}{|l|l|l|}
\hline \multicolumn{1}{|c|}{ Característica } & \multicolumn{1}{|c|}{ Serviço } & Manufatura \\
\hline $\begin{array}{l}\text { Propriedade (quem é o } \\
\text { responsável) }\end{array}$ & $\begin{array}{l}\text { Tende a ser ambígua ou o processo } \\
\text { tem vários donos }\end{array}$ & Definição geralmente clara \\
\hline \begin{tabular}{|l|l|l|}
\hline Fronteiras (pontos inicial e final) & Pouco nítidas, difusas & Claramente definidas \\
\hline \begin{tabular}{l|l|l|}
\hline Pontos de controle (regulam \\
qualidade e dão feedback)
\end{tabular} & Freqüentemente não existem & Estabelecidos de forma clara e formal \\
\hline $\begin{array}{l}\text { Medições (base estatística do } \\
\text { funcionamento) }\end{array}$ & $\begin{array}{l}\text { Difíceis de definir, geralmente não } \\
\text { existem }\end{array}$ & Fáceis de definir e de gerenciar \\
\hline $\begin{array}{l}\text { Ações corretivas (correção de } \\
\text { variações) }\end{array}$ & Geralmente ocorrem de forma reativa & Muito freqüentes as ações preventivas \\
\hline
\end{tabular}
\end{tabular}

Fonte: Baseado em Lowenthal (1994). 
sica com relação à estrutura organizacional. Essas características são discutidas a seguir.

Os processos de negócio são ligados à essência do funcionamento da organização (Dreyfuss, 1996). Eles são típicos da empresa em que operam e são muito diferentes de uma organização para outra. Eles têm o suporte dos sistemas que têm sido desenvolvidos ao longo de décadas de desafios e aperfeiçoamento. Numa seguradora, por exemplo, um importante processo de negócio é o da emissão da apólice, que se inicia com o preenchimento da proposta de seguro e termina com o preenchimento da apólice e sua remessa ao segurado. O Quadro 5 mostra exemplos de processos característicos de algumas indústrias selecionadas.

Os processos organizacionais geralmente produzem resultados imperceptíveis para os clientes externos, mas são essenciais para a gestão efetiva do ne- gócio. O suprimento de material é um processo organizacional nas empresas não fabris. Os processos gerenciais incluem as ações que os gerentes devem realizar para dar suporte aos demais processos de negócio. A avaliação da qualidade do atendimento aos pedidos dos clientes é um processo gerencial típico em diversas organizações.

Os processos organizacionais e gerenciais são processos de informação e decisão. Eles podem ser verticais e horizontais. Os processos verticais usualmente se referem ao planejamento e ao orçamento empresarial e se relacionam com a alocação de recursos escassos (fundos e talentos). Os processos horizontais são desenhados tendo como base o fluxo do trabalho. ${ }^{3}$ $\mathrm{O}$ trabalho nos processos horizontais pode ser realizado de diversas maneiras, gerando três tipos de processos horizontais (laterais) (Galbraith, 1995): volun-

Quadro 4 - Classificação geral dos processos empresariais

\begin{tabular}{|c|c|c|c|c|c|c|}
\hline Processos & $\begin{array}{l}\text { Tipo } \\
\text { (a) }\end{array}$ & $\begin{array}{c}\text { Capacidade } \\
\text { de geração de } \\
\text { valor (b) }\end{array}$ & Fluxo básico & $\begin{array}{l}\text { Atuação } \\
\text { (c) }\end{array}$ & $\begin{array}{c}\text { Orientação } \\
\text { (d) }\end{array}$ & Exemplo \\
\hline \multirow[t]{2}{*}{$\begin{array}{l}\text { De negócio (de } \\
\text { cliente) }\end{array}$} & $\begin{array}{l}\text { De produção } \\
\text { física }\end{array}$ & Primários & Físico & Transformação & Horizontal & $\begin{array}{l}\text { Fabricação de } \\
\text { bicicletas }\end{array}$ \\
\hline & De serviço & Primários & Lógico & Transformação & Horizontal & $\begin{array}{l}\text { Atendimento de } \\
\text { pedidos de } \\
\text { clientes }\end{array}$ \\
\hline \multirow{3}{*}{$\begin{array}{l}\text { Organizacionais } \\
\text { (apoio aos } \\
\text { processos } \\
\text { produtivos) }\end{array}$} & Burocráticos & De suporte & Lógico & $\begin{array}{l}\text { Integração } \\
\text { horizontal }\end{array}$ & Horizontal & Contas a pagar \\
\hline & Comportamentais & De suporte & Lógico & Não se aplica & Não definida & $\begin{array}{l}\text { Integração } \\
\text { gerencial }\end{array}$ \\
\hline & De mudança & De suporte & Lógico & Não se aplica & Não definida & $\begin{array}{l}\text { Estruturação de } \\
\text { uma nova } \\
\text { gerência }\end{array}$ \\
\hline \multirow[t]{3}{*}{ Gerenciais } & $\begin{array}{l}\text { De } \\
\text { direcionamento }\end{array}$ & De suporte & De informação & $\begin{array}{l}\text { Integração } \\
\text { horizontal }\end{array}$ & Vertical & $\begin{array}{l}\text { Definição de } \\
\text { metas da } \\
\text { empresa }\end{array}$ \\
\hline & De negociação & De suporte & De informação & $\begin{array}{l}\text { Integração } \\
\text { horizontal }\end{array}$ & Vertical & $\begin{array}{l}\text { Definição de } \\
\text { preços com } \\
\text { fornecedor }\end{array}$ \\
\hline & De monitorização & De suporte & De informação & $\begin{array}{l}\text { Medição de } \\
\text { desempenho }\end{array}$ & Vertical & $\begin{array}{l}\text { Acompanhamento } \\
\text { do planejamento } \\
\text { e orçamento }\end{array}$ \\
\hline
\end{tabular}

Fonte: Adaptado de (a) Rummler e Brache (1990); (b) James Martin (1996); (c) Susan Mohrman (1995); (d) Jay Galbraith (1995). 
tários (ocorrem por meio do contato voluntário entre os membros do grupo por iniciativa dos envolvidos), formais (definidos previamente por meio de documentos formais) e coordenados (que exigem times de organização mais complexa e formal).

\section{CARACTERÍSTICAS ESSENCIAIS DOS PROCESSOS EMPRESARIAIS}

De maneira geral, os processos nas empresas podem ser internos (quando têm início, são executados e terminam dentro da mesma empresa) ou externos. Os processos podem, também, ser inter ou intra-organizacionais (quando envolvem diversas empresas diferentes para a sua realização). Como já foi mencionado, os processos empresariais podem também ser horizontais e verticais, dependendo da sua orientação básica com relação à estrutura or-

Independentemente do tipo de estrutura organizacional escolhido pela empresa, algumas atividades importantes exigirão coordenação entre os departamentos. Os processos horizontais são processos de informação e decisão criados para a coordenação das atividades que se espalham por várias unidades organizacionais (Galbraith, 1995). São essenciais para prover a coordenação lateral necessária para a execução adequada dessas atividades.

Com relação à capacidade de geração de valor para o cliente, os processos podem ser primários, quando incluem as atividades que geram valor para o cliente, ou de suporte, que são os conjuntos de atividades que garantem o apoio necessário ao funcionamento adequado dos processos primários (Martin, 1996). É importante notar que os processos primários são os processos de negócio e que os processos organizacionais e os gerenciais, de acordo com essa definição, são processos de suporte. O Quadro 6 apresenta exemplos de processos empresariais genéricos, organizados nas três categorias fundamentais aqui definidas. ganizacional da empresa.

A primeira característica importante dos processos é a interfuncionalidade. Embora alguns processos sejam inteiramente realizados dentro de uma unidade funcional, a maioria dos processos importantes das empresas (especialmente os processos de negócio) atravessa as fronteiras das áreas funcionais. Por isso mesmo, são conhecidos como processos transversais, transorganizacionais (cross-organizational), interfuncionais ou interdepartamentais. Também são conhecidos como processos "horizontais", já que se desenvolvem ortogonalmente à estrutura "vertical" típica das organizações estruturadas funcionalmente. Enquanto os times verticais correspondem aos componentes funcionais, geográficos e de produto da empresa, como é o caso da equipe de vendas, os times horizontais correspondem às pessoas que trabalham nos processos transorganizacionais, como, por exemplo, o processo de atendimento de pedidos de clientes.

A segunda característica importante dos processos de negócio é o fato de que eles têm clientes

Quadro 5 - Exemplos de processos característicos de algumas indústrias

\begin{tabular}{|l|l|}
\hline Processo genérico & Indústria \\
\hline Processamento de pedido de empréstimo & Bancos \\
Atendimento de sinistro & Seguros \\
Alocação de verbas orçamentárias & Governo \\
Retorno de mercadoria & Varejo \\
Preparação de refeições & Restaurantes \\
Manejo de bagagem & Linha aérea \\
Serviço de telefonista & Telecomunicações \\
Serviço de reservas & Hotéis \\
\hline
\end{tabular}

Fonte: Adaptado de Rummler e Brache (1990). 
(Davenport e Short, 1990). O conceito de processo empresarial associa-se à idéia de cadeia de valor ${ }^{4}$, com a definição de fluxos de valor ${ }^{5}$ : uma coleção de atividades que envolvem a empresa de ponta a ponta com o propósito de entregar um resultado a um cliente ou usuário final. Nesses termos, as value streams não correspondem ao conceito de cadeia de valor proposto por Porter, visto que ela se refere à empresa como um todo, já que elas ocorrem dentro da organização. Esse cliente, ao qual o resultado deve ser entregue, pode ser interno ou externo à organização. Nesse sentido, a empresa é uma coleção dos fluxos de valor voltados à satisfação das expectativas de um determinado grupo de clientes. Os processos utilizam os recursos da organização para oferecer resultados objetivos aos seus clientes (Harrington, 1991).

A definição dos processos na empresa é essencialmente dinâmica, mudando com o tempo. Novos componentes vão sendo adicionados e outros são adaptados à medida que o ambiente muda, a empresa cresce $\mathrm{e}$ o conhecimento especializado se desenvolve. O funcionamento do processo precisa, então, ser adaptado, de modo que possa se adequar à nova situação.

\section{POR QUE OS PROCESSOS SÃO IMPORTANTES}

O futuro vai pertencer às empresas que conseguirem explorar o potencial da centralização das prioridades, as ações e os recursos nos seus processos. As empresas do futuro deixarão de enxergar processo apenas na área industrial, serão organizadas em torno de seus processos não fabris essenciais e centrarão seus esforços em seus clientes (Gonçalves, 1997). Os processos industriais, especialmente os de manufatura, sempre tiveram seu desempenho acompanhado de perto pelas legiões de engenheiros de produção e técnicos da área industrial. Os processos típicos da área não fabril e das empresas que não têm área fabril, no entanto, passaram despercebidos por décadas.

Parte do sucesso que as empresas japonesas tiveram com relação às suas concorrentes americanas nas décadas de 80 e 90 decorreu do fato de terem as empresas japonesas descoberto (ou pelo menos implementado) o gerenciamento de processos (Davenport, 1994) muito antes de as empresas ocidentais entenderem a que o assunto se referia. O papel de destaque dado ao gerenciamento de processos na cultura corporativa japonesa garantiu que, em diversas ocasiões, muitas empresas daquele país tenham desenvolvido processos rápidos e eficientes em áreas-chave como desenvolvimento de produtos, logística, vendas e comercialização.

A utilização do conceito de processos nos fornece um conveniente nível de análise, menos detalhado que o do estudo do trabalho, mas muito mais descritivo que o modelo da "caixa preta" (Garvin, 1998). Além disso, permite-nos ter uma visão melhor do comportamento gerencial, mais integrada e abrangente. É indispensável também para possibilitar a análise adequada dos processos administrativos e gerenciais, tão importantes para o funcionamento dos processos essenciais da organização.

Quadro 6 - As três categorias de processos empresariais

\begin{tabular}{|c|c|c|}
\hline Ligados ao cliente ou de negócios & Organizacionais ou de integração & Gerenciais \\
\hline $\begin{array}{l}\text { - São ligados à essência } \\
\text { do funcionamento da } \\
\text { organização } \\
\text { - São suportados por outros } \\
\text { processos internos } \\
\text { - Resultam no produto ou } \\
\text { serviço que é recebido pelo cliente }\end{array}$ & $\begin{array}{l}\text { - São centrados na organização } \\
\text { - Viabilizam o funcionamento } \\
\text { coordenado dos vários subsistemas } \\
\text { da organização } \\
\text { - Garantem o suporte adequado aos } \\
\text { processos de negócio }\end{array}$ & $\begin{array}{l}\text { - São centrados nos gerentes e nas suas } \\
\text { relações } \\
\text { - Incluem ações de medição e ajuste do } \\
\text { desenvolvimento da organização } \\
\text { - Incluem as ações de suporte que os } \\
\text { gerentes devem realizar }\end{array}$ \\
\hline $\begin{array}{l}\text { - Vendas } \\
\text { - Desenvolvimento de produtos } \\
\text { - Distribuição } \\
\text { - Cobrança } \\
\text { - Atendimento de pedidos } \\
\text { - Atendimento de garantia }\end{array}$ & $\begin{array}{l}\text { - Planejamento estratégico } \\
\text { - Orçamento empresarial } \\
\text { - Recrutamento e seleção } \\
\text { - Compras } \\
\text { - Treinamento operacional }\end{array}$ & $\begin{array}{l}\text { - Fixação de metas } \\
\text { - Avaliação do resultado da empresa } \\
\text { - Gestão das interfaces } \\
\text { - Alocação de recursos }\end{array}$ \\
\hline Processos primários & \multicolumn{2}{|c|}{ Processos de suporte } \\
\hline
\end{tabular}


A definição dos processos básicos é essencial para algumas estratégias de aperfeiçoamento do funcionamento das empresas, já que grupos serão alocados a eles, tanto para execução como para gestão. Os times horizontais, por exemplo, são criados a partir de unidades que naturalmente se aproximam para completar uma parte do trabalho a ser feito ou um processo dentro da empresa (Graham, 1994).

des. Para o pessoal de serviços, os processos são seqüências de atividades que são necessárias para realizar as transações e prestar o serviço (Ramaswamy, 1996). A importância dos processos de trabalho aumenta à medida que as empresas ficam com conteúdo cada vez mais intelectual ou nas empresas de conteúdo puramente intelectual (Quinn, 1992), afastando-se do modelo fabril.

Uma das mais importantes aplicações da idéia de processos é a simulação do funcionamento de novas formas operacionais de obtenção dos resultados da empresa, sejam eles produtos, sejam conquistas de qualquer outro tipo. Em projetos de redesenho de processos, por exemplo, uma das etapas de trabalho é o teste do protótipo do processo que está sendo redesenhado (Bennis e Mische, 1995). Outra aplicação

Identificar o processo como a maneira típica de realizar o trabalho é importante para definir a forma básica de organização das pessoas e demais recursos da empresa (Dreyfuss, 1996). O processo é um conceito fundamental no projeto dos meios pelos quais uma empresa pretende produzir e entregar seus produtos e serviços aos seus clientes. Além disso, muitos dos processos nas empresas são repetitivos e envolvem, no seu conjunto, a maioria das pessoas da organização.

Os processos são a fonte das competências "específicas da empresa" que fazem a diferença em termos de concorrência, além da influência que podem ter a estratégia, os produtos, a estrutura e a indústria (Keen, 1997). Os processos não criam apenas as eficiências de hoje, mas também garantem o futuro por meio de habilidades que se aplicam aos novos produtos. A rápida inovação dos processos pode resultar em capacitações organizacionais melhoradas (Kanter, 1997) que permitem, por exemplo, que os novos produtos sejam desenvolvidos mais rapidamente. É conhecido o caso das empresas industriais japonesas, que investiram $70 \%$ dos seus fundos de P\&D em inovação de processos, ao contrário das americanas, que investiram essa mesma proporção, mas no desenvolvimento de produtos. Os resultados muito superiores da indústria japonesa durante o período considerado provavelmente refletem as conseqüências dessa decisão.

Nas empresas de serviços, por exemplo, o conceito de processo é de fundamental importância, uma vez que a seqüência de atividades nem sempre é visível, nem pelo cliente, nem por quem realiza essas ativida- importante ocorre na implementação das mudanças previstas para a operacionalização de um novo processo. O sucesso do novo desenho para o processo depende fundamentalmente da sua operacionalização, e o desenho do processo é o blueprint, o mapa essencial do caminho a ser percorrido.

\section{A ESTRUTURA ORGANIZACIONAL POR PROCESSOS}

A organização orientada para processos está surgindo como a forma organizacional dominante para o século XXI (Hammer, 1996). Abandonando a estrutura por funções, que foi a forma organizacional predominante nas empresas do século XX, as empresas estão organizando seus recursos e fluxos ao longo de seus processos básicos de operação. Sua própria lógica de funcionamento está passando a acompanhar a lógica desses processos, e não mais o raciocínio compartimentado da abordagem funcional.

Faz sentido definir uma estrutura organizacional em torno de um processo como fluxo de trabalho. Tentar enxergar o funcionamento das empresas do ponto de vista dos processos é a mais eficaz maneira de escapar da "abordagem das chaminés" as empresas se organizam geralmente como conjuntos de unidades funcionais verticais isoladas umas das outras, operando em paralelo, sem muita interligação. Nesse modelo, os processos precisam atravessar as fronteiras entre as "chaminés" funcionais, com sensível perda de tempo, qualidade e capacidade de atendimento. 
A centralização das empresas nos seus processos levará a desenhos organizacionais muito diferentes dos que conhecemos atualmente. O primeiro estágio, não apenas previsível, mas que já está sendo adotado em muitas empresas, é o de redistribuir os recursos humanos e técnicos das empresas ao longo dos processos de negócios (Gonçalves, 1997). As parcerias e as redes de empresas estão surgindo como um segundo estágio desse movimento de reforma conceitual; dessa forma, nem todos os recursos essenciais para a operação da empresa se encontram dentro da empresa ou pertencem a ela. É de se prever, no entanto, que essa renovação organizacional venha a prosseguir, inclusive por caminhos ainda mais radicais. $\mathrm{O}$ fim das relações duráveis entre empresa e empregados, o realinhamento constante dos recursos para a adaptação aos desafios internos e externos e a redefinição do modelo de distribuição de responsabilidades e poderes nas organizações levarão a modelos organizacionais que, nesse momento, podemos apenas imaginar (Handy, 1989).

A implementação do ponto de vista do cliente na gestão das empresas praticamente exige que se faça o redesenho de seus processos de negócios. Afinal, as empresas convencionais sempre foram voltadas para si mesmas, projetadas em função de uma visão que privilegiava a sua própria realidade interna. A adoção de uma estrutura baseada nos processos significa, em geral, dar menos ênfase à estrutura funcional do negócio (Davenport, 1994) e empregar outros modelos organizacionais e de negócios (Gonçalves, 1998).

O raciocínio baseado em processos é essencial para o "tombamento" das organizações: os membros da equipe dão início ao trabalho e se asseguram de que o seu trabalho seja realmente realizado, estabelecem padrões para a avaliação da performance da equipe e de seus membros e dão apoio, encorajam e reconhecem as contribuições dos colegas de equipe. Essa forma de raciocínio dá maior ênfase ao processo que ao seu conteúdo.

Mudar a estrutura funcional da empresa para uma estrutura por processos implica definir a responsabilidade pelo andamento do processo, minimizar as transferências (para reduzir esperas, erros e fronteiras), maximizar o agrupamento de atividades e diminuir o gasto de energia (reunir as partes da empresa em menor número de locais ou empregar maciçamente os recursos de tecnologia de informação para diminuir gastos com transporte, armazenagem e deslocamento).
O emprego do conceito de processos na estruturação das empresas também leva ao desenvolvimento da função do "dono do processo" senciais são: garantir o andamento adequado ao fluxo do processo (pumping), a facilitação do relacionamento dos recursos aplicados ao processo (facilitating), a avaliação do funcionamento da empresa da perspectiva do processo e o aperfeiçoamento do funcionamento do processo.

\section{Mudar a estrutura funcional da empresa para} uma estrutura por processos implica definir a responsabilidade pelo andamento do processo, minimizar as transferências, maximizar o agrupamento de atividades
e diminuir o gasto de energia.

Uma vez que os processos empresariais e as atividades funcionais são ortogonais, em muitas situações, as pessoas são membros de equipes funcionais e de equipes de processos ao mesmo tempo. Essa forma atenuada de estrutura matricial apresenta várias das dificuldades características daquele tipo de estrutura, especialmente a duplicidade de comando e o conflito no emprego dos recursos da organização.

Outra consequiência da adoção da estrutura organizacional por processos é que não há sentido em se falar em centralização ou descentralização administrativa, uma vez que as decisões são tomadas por grupos de trabalho no local organizacional em que são necessárias. Como unidade central no desenho de organizações modernas, os processos enfrentam a crescente concorrência do conceito de network ${ }^{9}$.

\section{GESTÃO DO PONTO DE VISTA DO PROCESSO}

Tradicionalmente, as empresas ignoram seus processos, mas elas têm muito a ganhar ao se dedicarem a conhecê-los melhor (Hammer, 1998). De acordo com algumas pesquisas, o processo produtivo de um produto industrial genérico pode custar cerca de $10 \%$ do valor do produto e, durante décadas, esse processo tem sido o foco do esforço de otimização de resultados e redução de custos nas empresas (Harrington, 1991). Por 
outro lado, os processos que dão suporte aos processos produtivos são responsáveis por mais de $50 \%$ do custo dos produtos e somente nos últimos 10 ou 12 anos passaram a receber maior atenção. Além disso, somente agora os processos ligados à prestação de serviços começam a ser estudados de forma mais sistemática.

Entender como funcionam os processos e quais são os tipos existentes é importante para determinar como eles devem ser gerenciados para a obtenção do máximo resultado. Afinal, cada tipo de processo tem carac- e Brache, 1990). Afinal, são esses processos os geradores dos produtos que apresentam valor para os clientes da empresa. A gestão por processos se baseia, portanto, nos elementos básicos dos processos (Lipnack, 1997): tarefas executadas, reuniões realizadas, decisões tomadas, metas alcançadas e resultados produzidos pelo processo.

Gerenciar as empresas pelo ponto de vista dos processos parece ser um dos grandes desafios da gestão eficaz de recursos humanos nas empresas nas próximas décadas. ${ }^{10} \mathrm{~A}$ adoção do ponto de vista dos processos na gestão das empresas desenvolve e salienta a importância dos papéis ligados a processos ${ }^{11}$, que incluem a liderança do grupo, a ligação entre as pessoas, a facilitação dos mecanismos grupais, o desenvolvimento de conhecimento, o gerenciamento das agendas de compromissos e o suporte ao funcionamento das equipes (Graham, 1994). Isso implica treinamento e desenvolvimento das habilidades básicas em relações interpessoais, polivalência (multiskilling), treinamento interfuncional, solução de problemas, criatividade, coordenação e planejamento (Mohrman, 1995).

terísticas específicas e deve ser gerenciado de maneira específica. Os processos devem ter capacidade de resposta aos estímulos semelhante à demonstrada pelas criaturas vivas (Martin, 1996).

A visão horizontal das empresas é uma maneira de identificar e aperfeiçoar as interfaces funcionais, que são os pontos nos quais o trabalho que está sendo realizado é transferido de uma unidade organizacional para a seguinte (Rummler e Brache, 1990). São nessas transferências que ocorrem os erros e a perda de tempo, responsáveis pela maior parte da diferença entre o tempo de ciclo e o tempo de processamento nos processos empresariais.

A gestão por processos organizacionais difere da gestão por funções tradicional em pelo menos três pontos: emprega objetivos externos; os empregados e recursos são agrupados para produzir um trabalho completo; e a informação segue diretamente para onde é necessária, sem o filtro da hierarquia (Stewart, 1992). O sucesso da gestão por processos está ligado ao esforço de minimizar a subdivisão dos processos empresariais.

Durante muito tempo, as empresas foram dirigidas por meio de metas estabelecidas para as áreas funcionais, mas hoje as metas são definidas para os processos essenciais, que constituem um nível fundamental de avaliação de desempenho da organização (Rummler
Por outro lado, a gestão por processos traz desafios inéditos em termos de complexidade, já que é, por exemplo, relativamente simples explicitar a liderança de tarefa, mas é muito mais difícil tornar explícita a liderança de processo (social) (Lipnack, 1997). Além disso, na ausência da hierarquia, o pessoal precisa se organizar para garantir o andamento do processo. Os grupos auto-administrados são um conceito antigo e começaram a ser estudados de maneira sistemática nos anos 50 pelo pessoal do Tavistock Institute, nas minas de carvão inglesas.

Uma vez que as pessoas passam a trabalhar no processo, e não mais nas áreas da empresa que deixam de existir ou perdem muito de sua importância, a gestão dessas pessoas deve seguir modelos muito diferentes dos tradicionais. Num quadro de grande importância das pessoas na implementação de estruturas por processos e na gestão de organizações estruturadas de acordo com esse modelo, surgem perguntas inquietantes, para as quais não temos, ainda, as melhores respostas. Como trabalham as pessoas num processo? A quem respondem? Como se coordena o trabalho realizado no processo? Como avaliar a adequação e o desempenho das pessoas na organização por processos? Como estruturar a carreira e o desenvolvimento dessas pessoas? 
A abordagem de processos adota o conceito de hierarquia de processos e do detalhamento em níveis sucessivos. De acordo com esse conceito, os processos podem ser subdivididos em subprocessos e agrupados em macroprocessos. O nível de detalhe que importa é aquele mais adequado para a análise que se pretende realizar. Uma das importantes metodologias para o aperfeiçoamento das empresas adota três níveis de análise, sendo que um deles é exatamente o dos processos (Rummler e Brache, 1990).

Nem todos os processos têm a mesma importância para as empresas, tanto sob o ponto de vista dos resultados gerados como dos recursos envolvidos. Afinal, quais são os processos mais importantes na empresa? Aqueles de maior budget, os que têm maior impacto no funcionamento da empresa ou aqueles que são responsáveis pela maior parcela na geração de valor para o cliente? A prioridade dos processos para as empresas pode ser avaliada por meio de sua saliência (relativa importância para a empresa) e por seu valor (o valor econômico que ele gera). O conceito de EVA ${ }^{12}$ pode ser utilizado para priorizar os processos que merecem atenção concentrada por parte das empresas ${ }^{13}$.

Uma vantagem específica pode ser obtida e explorada pelas empresas que decidem investir no aperfeiçoamento de processos cuidadosamente escolhidos ${ }^{14}$. A experiência tem mostrado que o aperfeiçoamento de processos errados pode levar ao paradoxo dos processos: as empresas podem ter mau desempenho e até mesmo falir ao mesmo tempo que esforços de melhoria de processos estão sendo feitos para melhorar dramaticamente a eficiência por meio da economia de tempo e dinheiro e melhorando a qualidade do produto e o serviço ao cliente. Muitas vezes, os resultados são dramáticos em termos de processos individuais, mas os resultados globais são decepcionantes (Hall et al., 1993).

$\mathrm{O}$ aperfeiçoamento de processos tem importância fundamental na vantagem competitiva sustentada da empresa (Keen, 1997). Podemos apontar pelo menos quatro razões para ver o aperfeiçoamento de processos de negócio como uma chave para a vantagem competitiva na economia de hoje:

- aumenta a plasticidade organizacional: a mudança organizacional era a exceção, as empresas precisam ser flexíveis e capazes de se ajustar permanentemente;
- mudaram a economia e a natureza das mudanças e o que era possível conseguir com ajustes incrementais passou a exigir transformações radicais;

- aperfeiçoa as possibilidades dinâmicas da empresa, rotinas organizacionais que afetam a coordenação das atividades;

- reduz os custos de coordenação e transação no funcionamento da empresa.

\section{0 impacto da tecnologia na realização do} trabalho abrange desde alterações na forma de realização do trabalho individual até a maneira pela qual as empresas trabalham juntas em processos interorganizacionais, passando pela redefinição da maneira pela qual os grupos de pessoas realizam suas tarefas grupais.

\section{TECNOLOGIA E PROCESSOS}

A tecnologia tem um papel fundamental no estudo dos processos empresariais. Ela influencia tanto a forma de realizar o trabalho como a maneira de gerenciálo. Muitas vezes, o processo obedece a uma seqüência estrita de atividades, ditada pela sua tecnologia característica ou pela própria lógica do trabalho. A fabricação de produtos como bicicletas, camisas e livros se dá por meio de processos industriais cujas atividades devem ser realizadas em seqüência estrita. $\mathrm{O}$ fluxo de atividades do processo pode ser linear ou não, dependendo exatamente da tecnologia empregada na sua execução. Nos fluxos não-lineares as atividades podem ser realizadas em paralelo ou sem que obedeçam a uma seqüência predeterminada.

O impacto da tecnologia na realização do trabalho abrange desde alterações na forma de realização do trabalho individual até a maneira pela qual as empresas trabalham juntas em processos interorganizacionais, passando pela redefinição da maneira pela qual os grupos de pessoas realizam suas tarefas grupais (Gonçalves, 1993).

A tecnologia empregada induz algumas dessas modificações e facilita a ocorrência de outras. O emprego de sistemas integrados de gestão empresarial, por exemplo, exige que as pessoas passem a execu- 
tar suas tarefas de acordo com as rotinas e os procedimentos determinados pela tecnologia, por maior que seja a diferença com relação aos padrões anteriores. Por outro lado, a utilização de ferramentas de comunicação modernas, como o correio eletrônico e a teleconferência, viabiliza a montagem e o funcionamento de novos modelos de trabalho grupal, como

etc. As empresas têm investido na aplicação de TI aos seus processos mais importantes, de negócio ou não, exatamente para poderem aperfeiçoar o seu desempenho.

A utilização adequada da tecnologia pressupõe a definição da prioridade de tratamento, dedicando aos processos prioritários o esforço necessário de forma a garantir um resultado realmente importante para o negócio da empresa. Depende, também, da cuidadosa seleção dos processos a serem tratados. Aparentemente, parte da decepção com os parcos resultados obtidos com maciços investimentos em tecnologia na automação de processos nas empresas se deve ao fato de que muito daquele investimento foi feito em processos de retaguarda (back office) e em funções administrativas que geram pouco ou nenhum

os grupos interfuncionais remotos. Por causa disso, a tecnologia é considerada a ferramenta do redesenho de processos por excelência (Gonçalves, 1995a).

A preocupação com os processos empresariais deu origem ao desenvolvimento das chamadas "disciplinas de processo"15. Quando utilizadas de forma consistente na empresa, permitem que as pessoas assumam mais responsabilidades, adotem mecanismos mais eficazes de participação na realização do trabalho (Kanter, 1997) e empreguem melhores meios de comunicação e produção.

Depois de décadas de ostracismo, entender e estudar os processos nas empresas resgata a importância do estudo do trabalho nas organizações (Gonçalves, 1995b). O estudo do trabalho analisa a forma pela qual ele é realizado e os recursos que são necessários para a sua execução. Procura entender a lógica da forma como os resultados são obtidos e ajustar as atividades e a tecnologia empregada de maneira a otimizar o emprego dos recursos e a eficiência geral dos processos.

Entre todas as tecnologias empregadas nas empresas, a tecnologia de informação (TI) tem importância especial para a abordagem de processos. Além da sua utilização na automatização de tarefas e na própria execução dos processos, ela pode ser empregada em diversas atividades de apoio e gestão desses processos: na visualização do processo, na automatização do que é interessante automatizar na execução e na gestão do processo, na sincronização das atividades, na coordenação dos esforços, na comunicação dos dados, na monitoração automática do desempenho, valor para o cliente da empresa. O resultado que foi possível obter desse investimento não chega a ser percebido pelo cliente externo. ${ }^{16}$

\section{CONCLUSÃO}

Muitas empresas já fizeram esforços para melhorar seus processos, o que não significa que se tenham tornado centradas nos seus processos (process centered) nem que estejam fazendo as coisas da melhor maneira possível. Também não quer dizer que estejam obtendo o melhor resultado possível nem que estejam centrando seus recursos e esforços no seu cliente final.

A falta de um entendimento claro sobre o conceito de processo e a aplicação apenas pontual desse conceito na administração das empresas podem explicar parte dessa limitação na obtenção de resultados pelas nossas empresas. Ainda há muito o que fazer na aplicação do conceito de processo empresarial às empresas. O entendimento do funcionamento das organizações tem sido tão limitado, que ainda resta muito a ser feito para aperfeiçoá-lo.

A importância do emprego do conceito de processo aumenta à medida que as empresas trabalham com conteúdo cada vez mais intelectual, oferecendo produtos cada vez mais ricos em valores intangíveis. É maior ainda nas empresas de conteúdo puramente intelectual.

As técnicas e práticas de gestão empresarial deverão se adequar às organizações que estão se estruturando por processos. Hoje, há uma tendência em 
se focalizar nas atividades e habilidades individuais, com a conseqüente perda da visão de processo e das habilidades de equipe. Os modelos de monitora- ção do desempenho das empresas deverão ser redesenhados para que possam ser úteis na gestão dessas empresas. $\mathrm{O}$

\section{REFERÊNCIAS BIBLIOGRÁFICAS}

BENNIS, Warren, MISCHE, Michael. The $21^{\text {st }}$ organization San Diego: Pfeifer, 1995.

CAMERON, Kim et al. Downsizing and redesigning organizations. In: HUBER, George, GLICK, William (Eds.). Organizational change and redesign. New York: Oxford 1995.

DAVENPORT, Thomas. Reengenharia de processos. Rio de Janeiro: Campus, 1994.

DAVENPORT, Thomas, SHORT, J. E. The new industrial engineering: information technology and business process redesign. Sloan Management Review, v. 31, n. 4, Summer 1990

DREYFUSS, Cassio. As redes e a gestão das organizações. Rio de Janeiro: Guide, 1996.

GALBRAITH, Jay. Designing organizations. San Francisco: Jossey-Bass, 1995

GARVIN, David. The processes of organization and management Sloan Management Review, v. 39, n. 4, Summer 1998.

GONÇALVES, José Ernesto Lima. Características do trabalho no ambiente do escritório. Trabalho apresentado no Expomicro, São Paulo, julho de 1990

GONÇALVES, José Ernesto Lima. Reengenharia das empresas: passando a limpo. São Paulo: Atlas, 1995a. p.110-117: 0 papel transformador da tecnologia.

GONÇALVES, José Ernesto Lima. Um novo O\&M para recuperar o tempo perdido. RAE-Revista de Administração de Empresas, v. 35, n. 3, maio/jun. 1995b.
GONCALVES, José Ernesto Lima. Os novos desafios da empresa do futuro. RAE - Revista de Administração de Empresas, v. 37, n. 3, jul./set. 1997.

GONÇALVES, José Ernesto Lima. A necessidade de reinventar as empresas. RAE - Revista de Administração de Empresas, v. 38, n. 2, abr./jun. 1998.

GONÇALVES, José Ernesto Lima, GOMES, Cecília de Almeida. A tecnologia e a realização do trabalho. RAE Revista de Administração de Empresas, v. 33, n. 1, jan. fev. 1993.

GRAHAM, Morris, LeBARON, Melvin. The horizontal revolution. San Francisco: Jossey-Bass, 1994.

HALL, Gene et al. How to make reengineering really work. HBR, Nov./Dec. 1993

HAMMER, Michael. Towards the twenty-first century enterprise. Boston: Hammer \& Co., 1996. (Folheto).

HAMMER, Michael. A empresa voltada para processos. Management, jul./ago. 1998. (Entrevista).

HAMMER, Michael, CHAMPY, James. Reengineering the corporation. New York: HarperBusiness, 1994.

HANDY, Charles. The age of unreason. Cambridge: Harvard Business School Press, 1989.

HARRINGTON, H. James. Business process improvement. New York: McGraw Hill, 1991.

KANTER, Rosebeth Moss. Frontiers of management. Cambridge: Harvard Business School Press, 1997.
KEEN, Peter G. The process edge. Cambridge: Harvard Business School Press, 1997.

LIPNACK, Jessica, STAMPS, Jeffrey. Virtual teams. New York: Wiley, 1997

LOWENTHAL, Jeffrey N. Reengineering the organization. Milwakee: ASQC Quality Press, 1994.

MALHORTA, Yogesh. Business process redesign: an overview. s.I.: Brint Research Institute, 1998.

MALONE, Thomas et al. Tools for inventing organizations: toward a handbook of organizational processes. Boston: MIT, 1997.

MARTIN, James. Cybercorp. New York: Amacom, 1996.

MOHRMAN, Susan et al. Designing team-based organizations. San Francisco: Jossey-Bass, 1995.

MORRIS, Daniel, BRANDON, Joel. Reengenharia: reestruturando sua empresa. São Paulo: Makron, 1994.

QUINN, James Brian. Intelligent enterprises. New York: Free Press, 1992.

RAMASWAMY, Rohit. Design and management of service processes. Reading: Addison-Wesley, 1996.

RUMMLER, Geary, BRACHE, Alan. Improving performance. San Francisco: Jossey-Bass, 1990.

STEWART, Thomas. The search for the organization of tomorrow. Fortune, May 1992

\section{NOTAS}

0 título deste artigo foi inspirado no trabalho de James Martin, denominado Cybercorp (New York: Amacom, 1996).

Um extrato deste artigo foi apresentado no II Simpoi, realizado em outubro de 1999 .

1. Baseado em DAFT, Richard et al. Implications of top managers'communication choices for strategic decisions. In: HUBER, George, GLICK, William (Eds.). Organizational change and redesign. New York: Oxford, 1995.

2. Baseado em MOHRMAN, Susan et al. Designing teambased organizations. San Francisco: Jossey-Bass, 1995; RUMMLER, Geary, BRACHE, Alan. Improving performance. San Francisco: Jossey-Bass, 1990; GARVIN, David. The processes of organization and management, Sloan Management Review, v. 39, n. 4, Summer 1998.

3. Os processos horizontais também são conhecidos na literatura como laterais, como pode ser visto em obras de GALBRAITH, Jay. Competing with flexible lateral organizations. Reading: Addison-Wesley, 1994 e Designing organizations. San Francisco: Jossey-Bass, 1995

4. Podemos ver essa associação em DREYFUSS, Cassio. As redes e a gestão das organizações. Rio de Janeiro: Guide, 1996 e em Rummler e Brache (1990).
5. Definidos como value streams por MARTIN, James. Cybercorp. New York: Amacom, 1996.

6. Esse stovepipe approach é mencionado por inúmeros autores como uma das mais típicas características das estruturas organizacionais convencionais, e o nome foi adotado pela semelhança gráfica dos organogramas característicos desse tipo de empresas com as chaminés das fábricas.

7. "Tombamento" ou "tilting" da organização corresponde ao movimento figurado de "virar" o organograma da empresa, conforme proposto por GRAHAM, Morris, LEBARON, Melvin. The horizontal revolution. San Francisco: Jossey-Bass, 1994.

\section{Equivale à expressão process owner.}

9. Ver, por exemplo, LIPNACK, Jessica, STAMPS, Jeffrey. The teamnet factor. Essex Junction: Oliver Wight, 1993 e BIRCHALL, David, LYONS, Laurence. Creating tomorrow's organizations. London: Pitman, 1995.

10. A bibliografia a respeito é extensa e muito rica. Ver, po exemplo, GONCALVES, José Ernesto Lima. Os novos desafios da empresa do futuro, RAE - Revista de Administração de Empresas, v. 37, n. 3, jul./set. 1997 e FLOOD, Patrick et al. Managing without traditional methods. New York: AddisonWesley, 1996
11. Chamados de process roles por Lipnack e Stamps (1997)

12. EVA (economic value added) mede a capacidade de o empreendimento gerar riqueza acima e além das expectativas dos acionistas. Confronta os ganhos obtidos com 0 custo e 0 risco do capital envolvido.

13. É importante salientar a distinção entre benefícios e valor gerados por um processo, como pode ser visto em Keen (1997)

14. Peter Keen chama essa vantagem de "the process edge": a vantagem pelo processo.

15. Disciplinas, nesse sentido, são abordagens compartilhadas por diversas pessoas envolvidas em resolver os mesmos problemas em diferentes oportunidades.

16. Um dos mais famosos pesquisadores desse assunto, Paul Strassmann, publicou diversos livros e artigos a respeito desta desproporcionalidade entre investimentos e resultados da tecnologia de informação. 